\title{
Implant Complications
}

\author{
Ma Angeles Sánchez Garcés, Jaume Escoda-Francolí \\ and Cosme Gay-Escoda \\ University of Barcelona, Faculty of Dentistry, \\ Spain
}

\section{Introduction}

Implant treatment is regarded as a safe technique with high rates of success ( Adell et al., 1981; Adell et al., 1990; Buser et al., 1997; Buser et al., 2000; Wennström et al., 2005). Nevertheless, it has, as every surgical procedure, several complications that can occur and that must be known in order to prevent or solve them. Implantology is an ever growing field that is reaching the practice of general dentists due to the simplification of technical procedures. Specialists in oral surgery now perform more demanding procedures, along with general dentists, they must pay special attention during the learning curve in order to avoid risks.

The osseointegration process is considered to be safe and durable by both patients and dentists, for this reason, implants are considered as the first option to treat almost all cases of complete or partial edentulism. Regarded as a problem free procedure, it's demand is increasing. Despite the severe complications index is low, risk evaluation must be conducted systematically during the preoperatory stage based on clinical history, thorough exploration and if necessary consulting other specialists, dentists or physicians. Only by using a good work protocol, we can detect the local and systemic risk factors that could determine the success of the treatment and allow us to implement preventive measures if needed.

Parameters concerning systemic risks and their categories were well established in the $2^{\text {nd }}$ ITI Consensus's Conference (Buser et al., 2000) there are also excellent systematic reviews (Bornstein et al., 2009). If our interest is to know about local factors that can negatively interfere in the success of the treatment or even cause serious local or general complications, we can consult several reviews or case reports (Cochran, et al., 2009).

It is mandatory to classify all those clinical complications that can arise in this chapter, so we should differentiate between two concepts: accidents and complications (Annibali et al, 2009).

- Accidents always happen during surgical procedures.

- Complications appear lately, once surgery is already performed. There are two kinds of complications, depending on the time they emerge: early and late.

- Failures occur when the professional and/or the patient do not obtain the desirable results.

- Iatrogenic acts are regarded as accidents, complications or failures caused by a deficient praxis of the professional. 
The majority of problems that can arise in an implantology treatment are accidents, complications or iatrogenic errors, and are a consequence of an inadequate indication, poor quality or quantity of bone, an erroneous surgical technique, infections, lack of oral hygiene, smoking habit, systemic diseases that were poorly controlled, et cetera. Failures of implants normally occur once they are correctly osseointegrated, have developed an acceptable masticatory function and are the consequence of lost of bone support derived from a periimplantitis produced by the presence of bacterial plaque and/or overload.

Early complications can be included in the following group: infection, edema, ecchymosis and hematoma, emphysema, bleeding, dehiscence of the area and sensitive alterations; and in the group of late complications we can distinguish: mucoperiosteal flap perforations, maxillary sinusitis, mandibular fractures, loss of osseointegration, bone defects, periimplant lesions and infections (Annibali et al., 2009). Nevertheless, some of them, like bleeding, could appear at any moment during the treatment. We will not comment prosthetic complications or periimplantitis because they will be explained in other chapters.

Other authors classify complications as general or local, depending on their etiology. We prefer to describe these topics as they arise in the course of the treatment.

\section{Intraoperative accidents}

As we said previously, we define intraoperative accidents as those events that can occur during surgery. Their severity ranges from minimum to maximum values.

Among accidents we can include: Badly placed implants, bleeding episodes, lesions of soft tissues, and on an adjacent tooth, lack of primary stability, dehiscences and osseous fenestrations, implant displacement to maxillary sinus, mandibular fracture, broken instruments, aspiration or swallowing of instruments:

\subsection{Malposition or angulation of an implant}

It is advisable to assess the characteristics of the edentulous zone subject to rehabilitation using clinical and radiological CT, or cone beam CT imaging (Dreiseidler et al., 2009) at the time of devising an implantology treatment. Sometimes, this is not possible and the option then is to use short or tilted implants that can increase the availiable bone length by $50 \%$ when tilted aproximately $30^{\circ}$ or" by avoiding anatomical structures (menton nerve, maxillary sinus).

A wrong planning that involves a malposition or an overangulation, would represent an obstacle for carrying out the prosthetic restoration, while it also would deteriorate long-term implant viability throughout the implant treatment.

Angulation, in the case of a single implant, increases tension forces between the implant and the bone. However, angulation of implants located at very distal positions reduce forces supported by the periimplant bone (Bellini et al., 2009).

In the event that, as a result of a negligence or bone deficit, an implant may have been placed with an angulation that makes it dysfunctional, it is suggested the use of a repositioning system that has yielded excellent results and which is based on the osteogenic distraction of a bone fragment containing the integrated implant (Gotta et al., 2008; Mendonca et al.,. 2008; Oduncuoglu et al., 2011). All of which improves esthetic effects, as well as the biomechanical behavior of the implant by correcting crown-root proportion, contour of soft tissues and the relation with neighboring teeth. The authors reported that 
the distraction rate is the usual value ( $1 \mathrm{~mm}$ per day) and the suggested consolidation period is 8 weeks, and confirm implant stability in time (Oduncuoglu et al., 2011).

\subsection{Bleeding}

Bleeding excessively is a common accident that can happen in some surgeries as a consequence of local-anatomical or systemic causes. Sometimes, patients are more prone to bleeding, since they are under a platelet antiaggregant treatment on a daily basis or have coagulation disorders (Garfunkel et al., 1999). This clinical situation is defined in the Group 2 of medical-systemic risk, where other disorders are also classified: irradiated patients (radiotherapy), those with Diabetes Mellitus (specially type I), patients with coagulation disorders (anticoagulated patients or those with haemostatic disorders) and severe smokers (Buser et al., 2000). Group I includes high risk patients: patients with serious systemic diseases (rheumatoid arthritis, osteomalacia, imperfect osteogenesis), immunodepressed (HIV, immunosupresory treatments), drug addicts (alcohol, etc.), unreliable patients (mental or psychological disorders).

Patients treated with anticoagulant medication usually have history of vascular or cardiac pathology (fibrillation, myocardial ischemia, valvular diseases or prosthesis, or thromboembolisms) (Lang et al., 2000). Probably, these patients would be included in the P1 or P2 risk classification groups of the ASA (American Society of Anesthesiology); P3 and P4 groups cannot undergo any surgical intervention until they are under treatment and included in a lower group. In general, the elderly are the majority of patients who need implantology solutions, which means that the probability of comorbidity is higher and therefore it is mandatory to know their medical history.

Generally, therapeutic options in these patients comprise two approaches: decrease or eliminate the anticoagulant therapy once patient and physician have assessed risks and benefits.

However, invasive treatments can be performed, as in the case of implantology procedures, without the interruption of medication and as long as values concerning International Normalized Ratio (INR) are $>4$, and adequate hemostatic measures are followed and, at the same time, efforts are made to use atraumatic surgery techniques; in this situation, the risk of bleeding should be similar to that seen in healthy patients who are not under surgical outpatient treatment ( Bacci et al., 2010). Anyway, it is advisable that any discontinuation of the anticoagulant therapy before any aggressive surgery (bone graft, extensive flaps, and maxillary sinus elevation) is discussed with the patient's physician, whereas patients should always be informed on the risk of procedures. It is recommendable to temporarily discontinue the anticoagulant treatment for 1-2 weeks, with previous physician's knowledge, when it is based on platelet antiaggregants (acetylsalicylic, acid, clopidogrel, ticlopidin, etc.) (Brennan et al., 2007; Sanz et al., 2009).

Data from recent studies also suggest that the risk of postoperative bleeding in this type of patients is low or almost negligible, while any bleeding complication can be handled with local intraoperative or postoperative measures suggested for dental extractions or dental implantations, where this is the standard procedure to assure local hemostasis (suture, compression, the use of hemostatic microfibrilar collagen gauzes, oxidized cellulose, reabsorbable fibrin, or mouth rinsing with $4,8 \%$ of tranexamic acid) (Bornstein et al., 2009; Napenas et al., 2009). In more severe cases of bleeding, it is proposed to use a nasal spray of desmopressin acetate (Nahlieli et al., 2011). 
The same procedure could be useful in those cases where bleeding is caused by a mild variety of Von Willebrand disease (Garfunkel et al., 1999). The rest of coagulation pathologies resulting from a lack of coagulation factors should be managed in conjunction with the Hematology Department to settle the adequate preoperative therapeutic measures. Patients should be advised, once intraoperative bleeding has been put under control and surgery procedures have concluded, to follow some postoperative instructions at home, which include the application of ice, compression, and the intake of a soft and cold diet; they also should be provided with a contact telephone in case of any emergency.

Other infrequent causes of bleeding are as follows: lesions in any sublingual, lingual, perimandibular, or submaxillary artery when performing surgeries in the lower and anterior area of totally edentulous patients who have a deficit in the quality and quantity of bone. Sometimes bleeding is less acute and can be perceived as a sublingual hematoma detected after few hours of performing the surgery (Mardinger et al., 2007). In other cases it involves an emergency that threatens patient's life and which requires a bimanual compression and subsequent referral of the patient to an hospital. A total of 18 clinical cases have been reported in the literature with this problem. Dubois et al. (Dubois et al, 2010) reported two cases that required a tracheotomy to solve an obstruction of the upper respiratory system due to a perforation of the lingual cortical that broke several sublingual vessels. Therefore, it is essential to do an exhaustive preoperative radiological exam that should include regular computerized tomography to appreciate the particular anatomy of each mandible, especially when placing implants in the premolar and canine area to avoid concavities and follow the major axis to the maximum (Dubois et al., 2010; Frenken et al., 2010). The onset of this complication is easily determined by a remarkable lingual protrusion caused by the swelling of the area below the tongue. In the event of a wound, it should be compressed by a ligature of the vessel involved as soon as it has been identified.

There is also a case report that describes an uncontrolled bleeding following a sinus lift procedure that caused a lesion on the artery that anastomoses the posterior superior alveolar artery with the infra-orbital one. Another case on a sinus lift procedure described an uncontrolled bleeding resulting from a lesion involving an artery that joined by anastomosis the posterior superior alveolar artery and the infra-orbital artery. Both arteries are branches of the maxillary artery that finds its way through an intraosseous passage located at a distance of $16.4 \mathrm{~mm}$ from the bone crest (Elian et al., 2005). The process of opening the lateral wall of the maxillary sinus, to connect the upper and lower osteotomies with vertical right and left osteotomies, can produce a lesion on this vessel that could lead to an intense and pulsating bleeding in a remote and difficult place to access (Testori et al., 2010). Lee (Lee, 2010) reported a case of a bleeding of an $8,1 \mathrm{~mm}$ artery above the alveolar crest that was finally controlled (after multiple attempts of compression and using bone wax) with the administration of local anesthesia and vasoconstrictor agents, as well as the application of gauzes soaked in bovine thrombin to help in the last coagulation process of transforming fibrinogen into fibrin. Once again, it is strongly recommended to carry out an exhaustive tomography study of this area before performing this surgical technique.

\subsection{Soft tissue lesions}

A series of lesions can occur in soft tissues, such as burn lesions on the labial mucosa resulting from overheating of the hand piece head, flap tear due to an excessive traction or as a consequence of an incorrect use of instruments or any abrupt movement by the patient or the surgeon, among other causes (Ozcelik et al., 2005). These lesion can be mostly avoided 
through a careful management of tissues or by sedating the patient and thus prevent the occurrence of stress situations for both surgeon and patient.

\subsection{Lesions of adjacent teeth}

The malposition of an implant may lead to the lesion of an adjacent tooth, where this involves a lesion on the radicular surface or the root apex and a subsequent post-operative pulpitis, or periodontitis, that must be treated, in the majority of cases, by endodontic means, while sometimes it involves the non-integration of the implant because of the inflammation. It is of the utmost interest to study the axis of those teeth delimiting the edentulous space to be rehabilitated with implants to decide, before surgery, implant axis and thus choose the most convenient one, or reduce its length to curb its convergence and thus prevent this type of dental iatrogenic lesions. On some other occasions, the inflammatory-infectious origin in the apical zone is a tooth adjacent to the implant and this is especially due to the proximity of the tooth to the implant and to the time elapsed since the endodontic procedure on the tooth was performed, so the risk of a retrograde periimplantitis increases when the distance between tooth and implant apexes is shorter and when the lapse of time between the endodontic procedure and the implantation is also shorter (Quirynen et al., 2005; Tozum et al., 2006; Zhou et al., 2009).

\subsection{Lack of primary stability}

Primary stability is determined by bone density and cortical bone thickness, a fact that explains why it is easier to obtain a better stability in mandibular implants than in maxillary ones (Seong et al., 2009) as it entails preparing the implant bed (incorrect tapping, too-wide ostectomy) or in those cases in which the implant is immediately placed after an exodontic procedure (Becker et al., 2011; Cooper, 2010) and becomes manifest by insertion torque values, so a low insertion torque value $(<10 \mathrm{Ncm})$ will determine a higher risk of osseointegration failure (type bone IV), whereas a too-high torque value $(>45 \mathrm{Ncm})$ could lead to a bone compression which would result in a bone necrosis (type bone I), and in an osseointegration failure (Neugebauer et al., 2009).

Cooper (Cooper, 2010) described, in a study on 1084 implants, that there was a 6.43-fold lower risk of primary implant stability failure in the anterior mandible than in other locations. The maxilla had a 2.7-fold higher risk of primary stability failure versus the mandible. Females had a 1.54 higher risk of primary implant stability failure versus men; implants less than $15 \mathrm{~mm}$ in length had a 1.49-fold higher risk of primary implant stability failure versus longer implants.

Rough surfaces, a cone design of implants, and the use of osteotomes in the management of the implant bed can increase primary stability on low-quality bones (Javed et al., 2011; Padmanabhan \& Gupta, 2010). When it is not possible to implement the aforementioned solutions, it would then be advisable to replace the unstable implant for a rescue implant, with a wider diameter and/or a longer length, or wait, as a final resort, 6-8 weeks before a surgical re-intervention.

\subsection{Dehiscences and fenestrations}

Osseous dehiscences and fenestrations in the vestibular cortical bone during the placement of implants constitute a risk factor for the healing process of periimplant tissues (fig. 1). In 
these cases, bone regeneration in parallel with implant placement is therefore mandatory and can be achieved using different materials, such as autologous, allogenic or xenolog bone, or phosphocalcium materials, such as hydroxypatite or tricalcium phosphate, in conjunction with non-reabsorbable or reabsorbable membranes (Becker et al., 2009; Jung et al., 2009; Oh et al., 2003; Rosen \& Reynols, 2001; Mayfield et al., 1997), in addition to associated growing factors, or in combination with different materials (Hassan, 2009.)

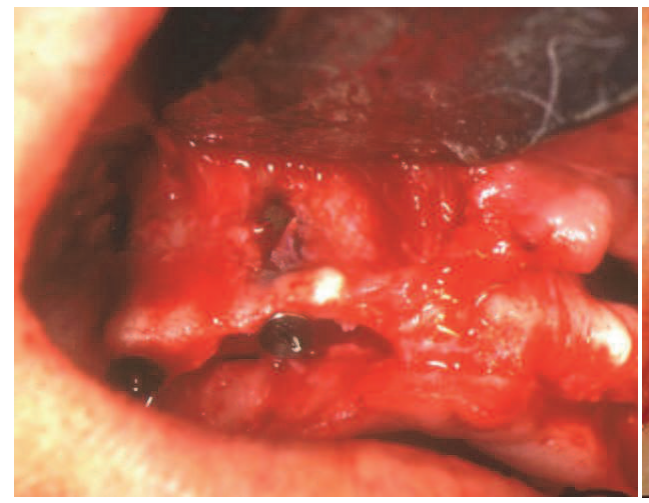

a)

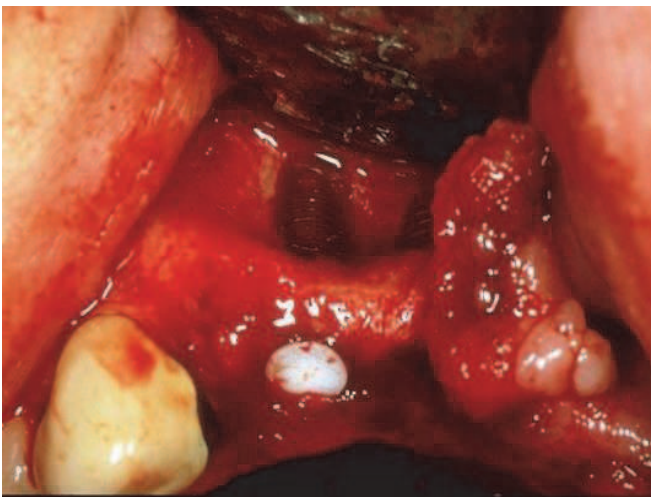

b)

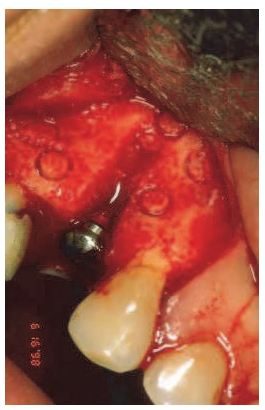

c)

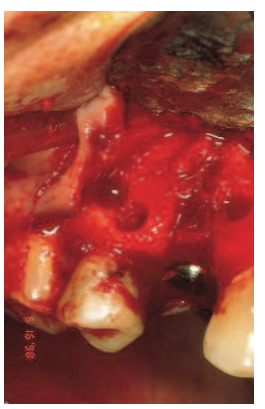

d)

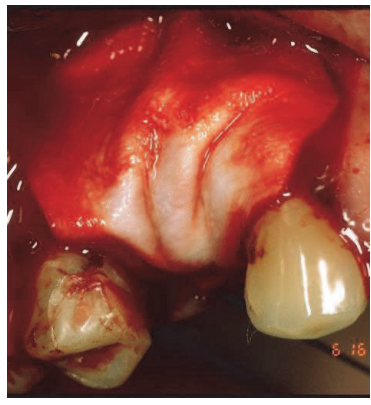

e)

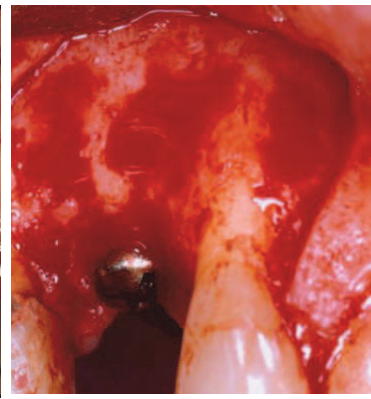

f)

Fig. 1. (a, b) Osseous fenestration. (c) Osseous dehiscence. (d) Autologous bone chips. (e) Collagen membrane. (f) Clinical result at 5 months.

Results are subject to the magnitude and morphology of the defect to be regenerated, the stability of both the material and the membrane, the maintenance of the space, the reabsorption time of the membrane, on the assumption that it is reabsorbable since its efficiency, or that concerning the fenestration of non-reabsorbable membranes (it could trigger the onset of an infection). All these factors determine the final results (fig. 2). 


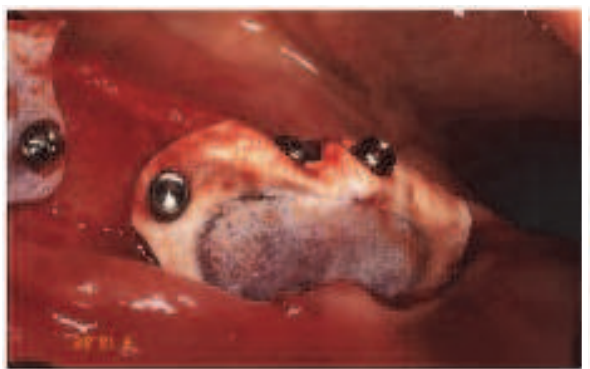

(a)

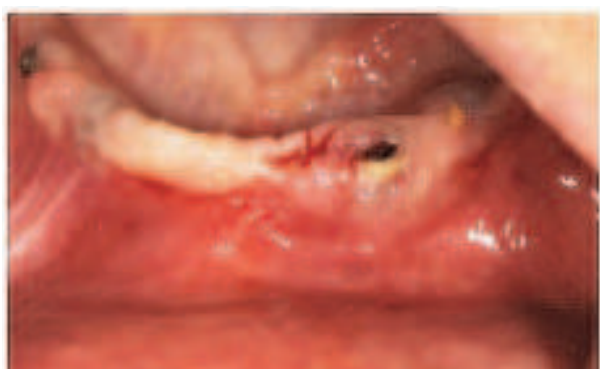

(b)

Fig. 2. (a) PTFE membrane covering a bone defect. (b) Membrane fenestration at 15 days control.

These accidents happen when implants are placed in a prosthesis-guided axis-position, but even though guided bone regeneration principles may have been followed, the main problem lays in a good wound-closure that may allow a primary scarring. It is necessary for the design, and the management and release of the flap to allow a wider extension, and thus achieve a better cover and tension-free surgical site (Hur et al., 2010). Smoker and diabetic patients have an added risk factor since scarring is more difficult and this can significantly jeopardize results, since the success of bone regeneration in non-smokers may reach $95 \%$ compared to $65 \%$ in those who smoke; furthermore, inflammation and exposure of membranes is greater (Garg, 2010; Abt, 2009; Cochran et al., 2009; Lindfors et al., 2010) (Fig. 3).

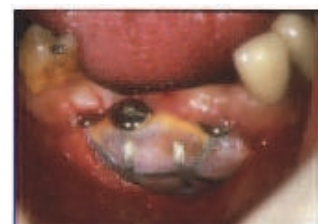

a)

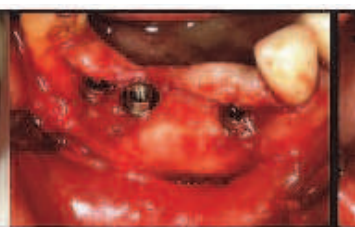

(b)

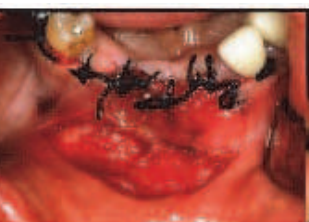

(c)

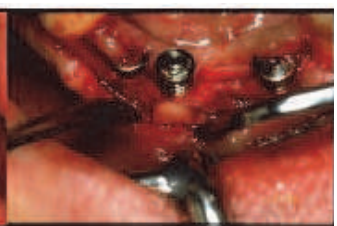

(d)

Fig. 3. (a) Wound dehiscence in a GBR with PTFEe Ti reinforced at 5 weeks of maintenance. (b) Image after the membrane was retrieved. (c) Bipedicular flap covering the new tissue. (d) Clinical result after 5 months.

Osseous dehiscences and bone fenestrations can pass unnoticed in those cases when an implant is immediately placed following an exodontic procedure or a transmucosal flapless surgery (Steigmann, 2008); so, as to values concerning probing depth and insertion level, results are less favorable when compared with implants placed in integral alveolar crests (Siciliano et al., 2009). This risk should be prevented by a correct exploration of the alveolus before inserting the implant (Nahlieli et al., 2011).

It is not recommendable to carry out guided bone regeneration (GBR) during the intraoperative period when the exposed surface of the implant is, in the event of dehiscence, equal or greater than $2 / 3$ of its length.

Consequences could be more severe in the event of perforating the lingual cortical layer of the inferior jawbone in the inter-mental region, as abovementioned, so it is necessary to adequately arrange the implant axis in this situation and in all possible situations. This situation, though, could be prevented by requesting CT imaging studies (Parnia et al., 2010). 


\subsection{Implant displacement}

The invasion of the maxillary sinus by an implant can occur during or after the surgery as a result of an insufficient primary stability. It has been reported a case of an implant which had been implanted 9 months earlier during a maxillary sinus lift surgery, and which was found inside the sinus only a few days after having placed the fixture (Chappuis et al., 2009). Therefore, any implant could undergo a displacement at any time after having been fixed with a cover screw (osseointegration period), even avoiding regenerative techniques in a spontaneous and asymptomatic way, or even afterwards, at the time of connecting the healing abutment (Ridaura-Ruiz et al., 2009) (Fig. 4).

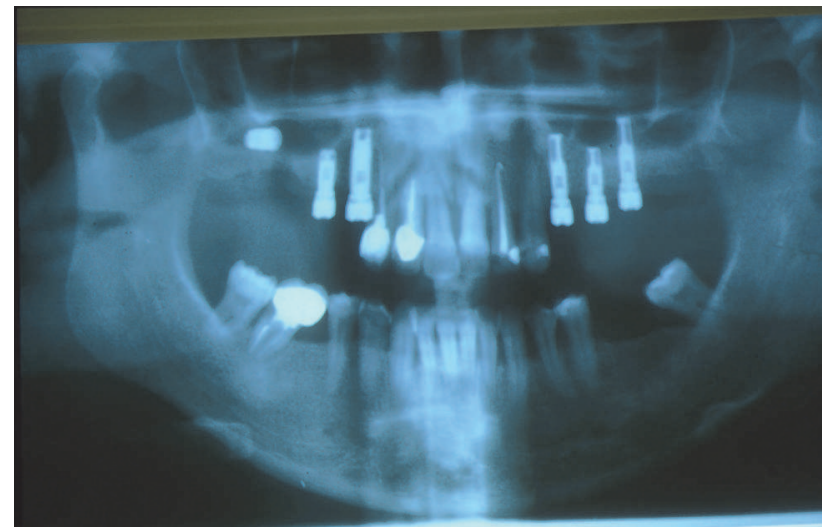

Fig. 4. Implant displaced within the course of a second stage surgery.

In general, implant displacements occur sometimes after an implant placement because there is an absence or loss of osseointegration and, therefore, of stability (low osseous density around it). Nevertheless, some authors report the displacement of implants into the maxillary sinus during their installation (Chappuis et al., 2009; Felisati et al., 2007; Haben et al., 2003). When this happens, the implant remains, in almost all the cases, lodged inside the sinus (Chappuis et al, 2009; Borgonovo et al, 2010), and can be removed a few days later by opening the lateral wall of the maxillary sinus (Haben et al., 2003) (Fig. 5), or by endoscopic via through a nasal window; a process that allows a considerable good access to the zone and a lower postoperative morbidity than when it is performed intraorally (Haben et al., 2003; Felisati et al., 2007; Galindo et al., 2005; Ramotar et al., 2010).

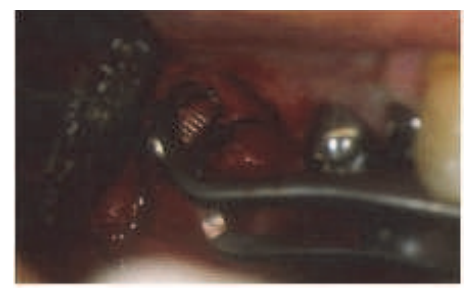

a)

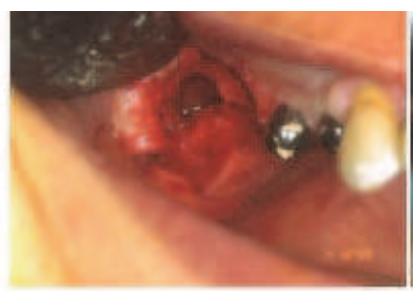

(b)

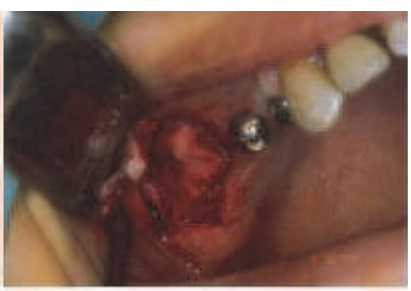

(c)

Fig. 5. (a) Implant retrieval through a lateral window. (b) Oro-antral communication. (c) Membrane covering the window. 
In these intra- or postoperative cases, authors recommend the immediate removal of the implant lodged in the maxillary sinus (Ramotar et al., 2010; Galindo et al., 2005; Felisati et al., 2007; Haben et al., 2003) through an intraoral or trans-nasal via that will prevent further associated complications; although it is in general asymptomatic condition, most patients suffer from a marked sinusitis. Another complication, in addition to the acute or chronic sinusitis, is the implant intrusion that occurs when it is not removed during its migration Felisati et al. and Haben et al. (Felisati et al., 2007; Haben et al., 2003) reported two cases of intrusions in which they found that two fixations had displaced from the maxillary sinus into the sphenoidal and ethmoidal sinuses, respectively, when they tried to remove them; the solution, though, should be to use an endoscopic nasal via. There is also a particular case describing a migration that ended in the orbital floor (Griffa et al., 2010) in its way from the maxillary sinus, and after an attempt to install a fixture in the alveolar bone. The article describes how the authors tried to aspirate the implant, which had penetrated deep into the zone and perforated the thin cortical bone of the orbital floor to end up lodged between the bone and the inferior rectus orbital muscle causing pain and diplopia. It was finally removed with general anesthesia and nasal endoscopy (Fig. 6).

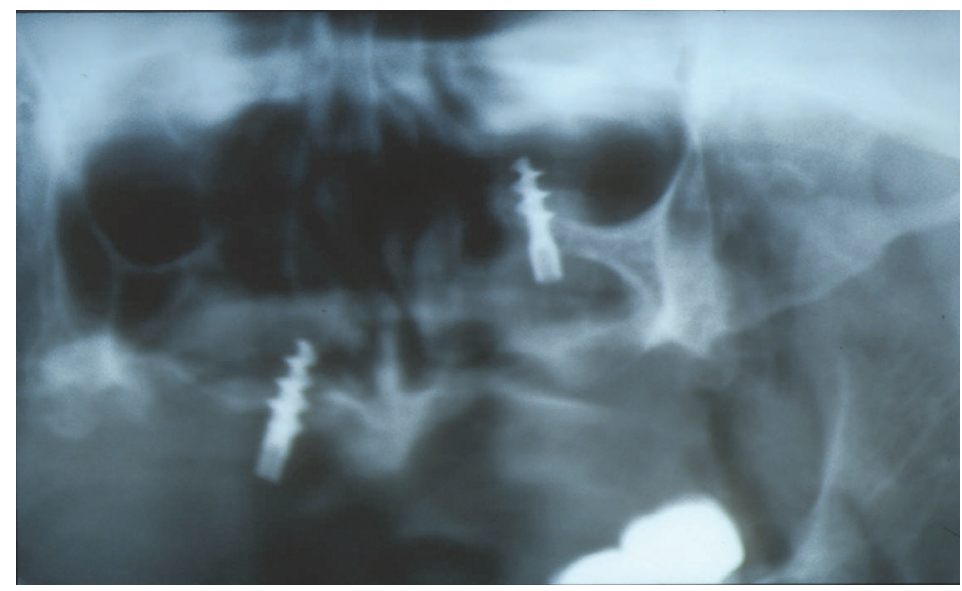

Fig. 6. Image of an implant migrated to the orbital floor.

To conclude, the positioning of an implant into the sinus is an infrequent event that does rarely occur during the placement of dental fixtures, or in the second phase. It is usually detected in the postoperative period and is in general ascribed to a lack of primary stability of the implant (a poor bone quality) (fig. 7). This complication could be prevented with an accurate surgical technique that would include using osteotomes to prepare the implant beds or a drill with a smaller diameter to that of the fixture, or using implants with a conical compressive form. If this complication finally occurs, it must be solved immediately and carefully in order to avoid any migration of this foreign body to a more harmful anatomical space. 


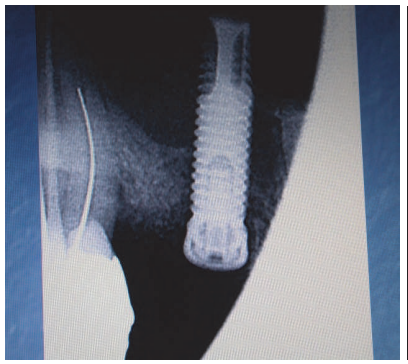

(a)

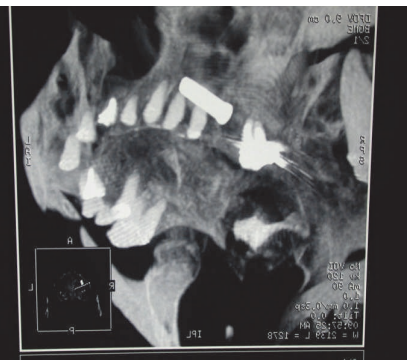

(b)

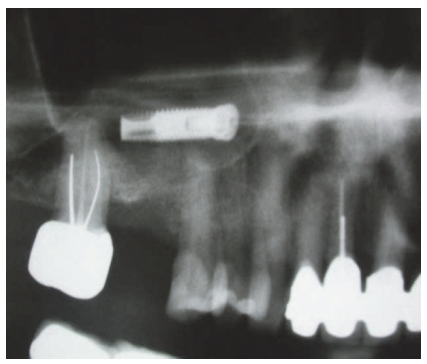

(c)

Fig. 7. (a) Implant installed (Summer's technique). (b) Control CT Scan after displacement and before second stage surgery. (c) Change of position.

Finally, it is worth mentioning a case report describing the migration of a zygomatic implant to the cranial fossa. This is a major complication that can end up with a cerebral lesion or an infection that must be prevented with a preoperative and postoperative three-dimensional radiographic study (Reychler \& Olszewski, 2010).

There are no publications about cases where the cortical nasal floor ended up perforated and the implant has subsequent migrated to this cavity. The fact of anchoring the fixture bicortically does not constitute any risk as long as the mucosa is preserved, whereas if it became perforated it would then lead to an infection complication because it would enable a direct contact with a septic cavity.

\subsection{Mandibular fracture}

Mandibular fracture, during implant placement, is associated with atrophic mandibles. The central area of the mandible has a greater risk for this complication because it has a poor vascular irrigation, which sometimes makes very difficult for the bone and periosteum to provide enough blood for the healing process derived from an implant placement (Chrcanovic \& Custodio, 2009). The bone in this area is usually sclerotic and undergoes severe resorption as a consequence of a large period of edentulism and also as a result of the pressure exerted by the prosthesis, which does accelerate the process. Technically, it is difficult to perform implant perforations in this zone without running the risk of overheating the surrounding bone; moreover, sometimes surgeons resort to bi-corticalized implants in this area, which increases the risk of a mandibular fracture, so patients should be informed before starting this surgical procedure (fig. 8).

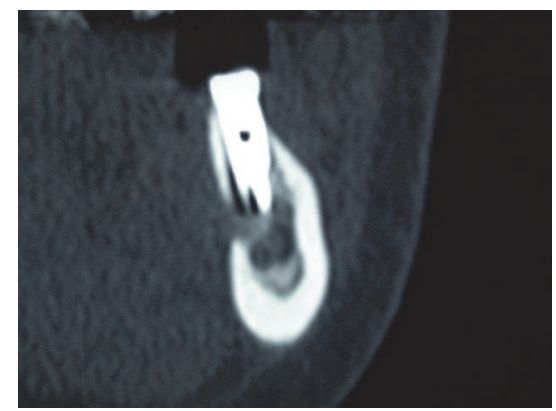

Fig. 8. Perforation of the lingual cortical during drilling. 
It is an infrequent complication that could start during surgery and subsequently evolve to a serious complication if, as Oh et al. report (Oh et al., 2010), the implant causes an infection when it becomes displaced from the fracture line to a sub-mandibular space.

The main treatment consists in the reduction and stabilization of the fracture with titanium miniplates (Oh et al., 2010; Tiwana et al., 2009), or resorbable miniplates. Nevertheless, other authors report less atraumatic techniques such as splinting implants with a Dolder bar to reduce and immobilize the fracture (Romanos, 2009).

Chrcanovic and Custodio (Chrcanovic \& Custodio, 2009) suggest, in order to prevent this complication in the management of thin mandibular alveolar crests, to increase width by performing bone grafts beforehand and through an accurate tomography imaging study to calculate these parameters with precision.

A case of a fracture and displacement of part of the lingual mandible cortical was reported, as a result of withdrawing a mono-cortical bone graft from the chin. The surgical procurement of a mono-cortical bone graft from the chin resulted in the fracture and displacement of part of the lingual mandibular cortical bone (Cordaro et al., 2004); it was decided not to perform any re-intervention due the lack of patient symptomatology.

\subsection{Neurosensory impairment}

Nerve lesions are both an intraoperative accident and a postoperative complication that can affect the infra-orbitary nerve, the inferior alveolar nerve, or its menton branch and the lingual nerve. Neurosensory impairment may occur at any time during implant surgery, including anesthesia administration, incision, raising a flap, as well separating it too tightly, during osteotomy preparation, bone augmentation, implant placement, suturing or any soft tissue swelling after surgery (Misch \& Resnik, 2010) (Fig. 9). These complications have a low incidence (reported between 0\%-44\%) (Misch \& Resnik, 2010). Symptomatology is of a large variety and depends on the severity of the axonal damage.

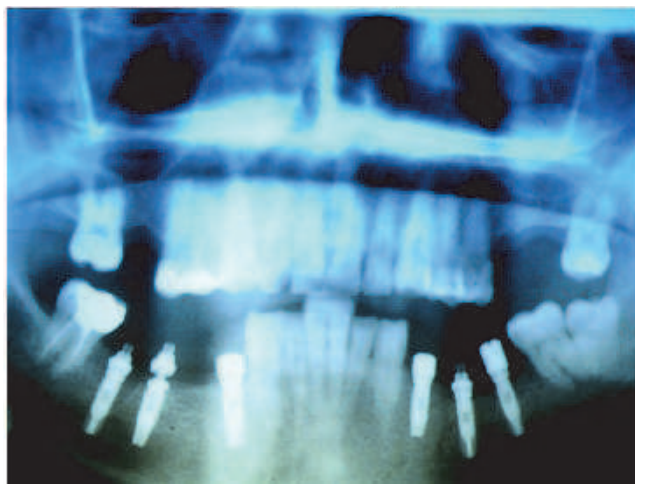

a)

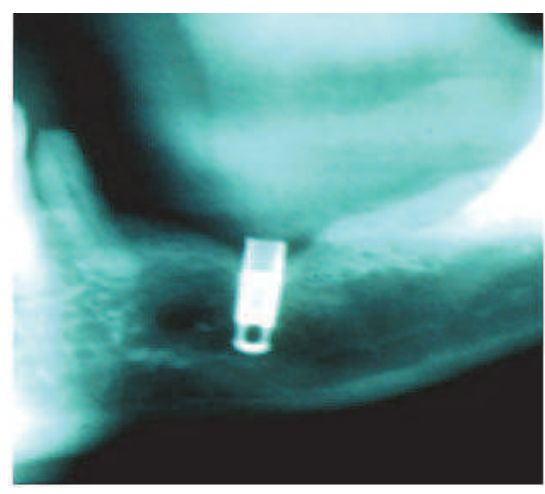

(b)

Fig. 9. ( $a, b)$. Several implants in contact to the Inferior Alveolar nerve in patients with postoperative paresthesia.

The complication could manifest as a paresthesia when the lesion is due to a nerve compression, or a minor stiffening of nerve fibers, without sectioning any of them (neuropraxia). Dysesthesia may occur in cases of nerve compression, traction, partial crush 
or stretching (axonotmesis) of nerve fibers with different intensities. Hypoesthesia or hyperesthesia may be caused by extreme stretching, complete crush and direct trauma on nerve fibers (neurotmesis); anesthesia and pain appear as consequence of a complete nerve section.

A very useful review about lesions and treatment algorithms may be found in a report published by Misch and Resnik (Misch \& Resnik, 2010). Treatments depend on the type of injury. The implant should be removed as soon as possible to avoid compression when radiological imaging reveals there is too much proximity between the implant and a nerve. Treatment with corticosteroids and non-steroidal anti-inflammatory drugs are indicated to control inflammatory reactions that provoke nervous compression. It seems that the topical application of dexamethasone $(4 \mathrm{mg} / \mathrm{ml})$ for 1 or 2 minutes enhances recovery, and when it is administered orally and in high doses within one week of injury, it has have shown to inhibit axon sprouting centrally and ectopic discharges from injured axons, and prevention of neuroma formation (Misch \& Resnik, 2010).

An intraoperative nerve section requires microsurgery techniques to reestablish nerve continuity. Nerves can be partially or completely damaged, and this aspect determines the prognostic of recovering the sensibility completely. Clinically, the evaluation of the neurosensorial loss should be checked at different moments to determine with precision the evolution of the lesion and, if necessary, refer the patient to a neurosurgery specialist (Misch \& Resnik, 2010; Greenstein et al., 2008). Hegedus et al. (Hegedus et al., 2006) propose an evaluation of the subjective symptoms and carry out an exhaustive neurosensory exploration of the patient's affected area to document all the written data referring this complication and thus evaluate patient's evolution. It is recommendable to resort to microsurgery if, after four months, patient's situation has not improved, pain persists and there is a remarkable loss of sensitivity.

Another nervous lesion could manifest in the form of an idiopathic facial pain, as the case reported by Queral-Godoy et al. (Queral-Godoy et al., 2006), on a lesion subsequent to the placement of two implants in the anterior region of a mandible. The prevalence in implantology is unknown, although it is estimated to be between 3-6\% of all the endodontic cases. The treatment suggested by these authors should basically comprise the administration of tricyclic antidepressant drugs, amitriptyline and benzodiazepines on a chronic basis. Rodriguez-Lozano et al. (Rodriguez-Lozano et al., 2010) describe another peculiar case of neuropathic pain that showed up eight months later after the surgical placement of eight dental fixtures.

Nahlieli et al (Nahlieli et al., 2011) propose to use a mini-endoscopic device to check the bottom of the surgical bed to detect any possible osseous defect; this technique could be interesting to prevent nervous lesions.

\subsection{Aspiration and swallowing of instruments}

When an accident involves the aspiration (Pingarron et al., 2010) or swallowing (Welcker et al., 2005; Worthington,. 1996) of an instrument (burs, screwdrivers, covering screws or healing abutments), it can become a vital emergency if the instrument has entered the airways. If the object has not been discharged from the respiratory track, it should then be necessary to perform a bronchoscopy. A special case describes the need to even perform a tracheotomy in a similar situation; the patient subsequently suffered a pneumothorax and a pleural effusion. Authors recommend general anesthesia in those cases in which there is the suspicion of any difficulty in the course of the procedure. 
For daily surgeries, it is strongly recommended to tie all tiny and slippery instruments regularly used during the procedure with silk ligatures so as to quickly recover them if they fall from the operator's hands, or else use a rubber dam (Bergermann et al., 1992).

In the event an object entered the digestive system, it would require carrying out a series of post-operative controls with the help of radiological imaging. A rich diet in fiber will also help solve this problem sooner. A gastroscopy or colonoscopy could also be mandatory in those cases in which the object remains stationery in the intestinal tract, while a proper medical follow-up will help see any progress of the object, or objects, through the digestive tract (Fig. 10). This type of accidents can occur in any of the sequences of the implant treatment.

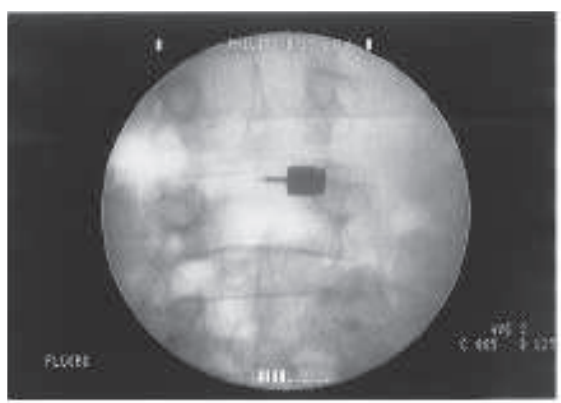

a)

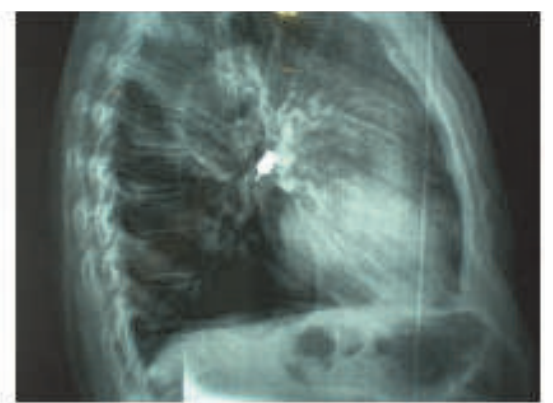

(b)

Fig. 10. (a) Images of a screw driver in the digestive tract. (b) Screw driver into pulmonary tissue.

\section{Early and late complications}

Early complications include: implant fracture, infection, edema, ecchymosis and hematoma, emphysema, bleeding, soft tissue dehiscence of the area and sensitive alterations. As to late complications we can distinguish: mucoperiosteal flap perforations, maxillary sinusitis, mandibular fractures, loss of osseointegration, periimplantitis (Annibali et al., 2009). Most of the complications described in this chapter, though, may occur early, or lately, or even be the consequence of a surgical accident or an iatrogenic act.

\subsection{Edema}

Swelling can appear after a surgical intervention, although it is more noticeable 24 hours after performing it. It can lead to trismus, lack of hygiene in the wound and discomfort to the patient. It normally decreases with time, and can easily vanish after a few days. Wide flaps, bone regenerating techniques, and surgery time are factors that trigger the occurrence of edemas and patient's susceptibility. The occurrence of edemas, and the need of analgesic and anti-inflammatory drugs is, in a statistically significant way, lower in guided flapless surgery, as can be seen in under-control studies (Arisan et al., 2010; Cannizzaro et ala., 2008), even in immediate implants after exodontic procedures (Cannizzaro et al., 2007) and immediately loaded implants (Cannizzaro et al., 2007; Cannizzaro et al., 2008; Merli et al., 2008; Arisan et al., 2010); however, a careful management of tissues, using non-excessive tension and bone-supported retrievers can minimize this effect along with the use of a cold pack, and non-steroid anti-inflammatories drugs; although in the event of a complex post- 
op, the administration of corticosteroids during a short period of time can be very helpful. Before the suspicion that the inflammation could compress any nervous structure, corticosteroids are crucial to minimize the risk of lesions (Misch \& Resnik, 2010).

\subsection{Bleeding, ecchymosis and hematoma}

Low-intensity bleeding is a frequent complication that must be solved as soon as possible, and it generally occurs on the basis of the surgical extension of the surgical procedure and the general condition of the patient. We recommend suturing all surgical wounds and compressing the zone with gauzes, as well as apply a cold pack, have physical rest, and the intake of a soft and cold diet to prevent an excessive bleeding after surgery. Nevertheless, the best method to avoid this problem is to write up a complete medical report from data provided by the patient's physician to collect any information on blood disorders. Sometimes we have to request a complete hemogram with coagulation tests to make clear the situation of a specific patient.

There are three main anticoagulants: coumarin, heparin and aspirin. Usually, they are prescribed to treat a number of cardiac or vascular disorders that include atrial fibrillation, ischemic cardiac disease, cardiac valvular disease, prosthetic cardiac valves, post-MI, deep venous thrombosis, pulmonary embolism, cerebrovascular accident, and many other disorders. Therefore, antiaggregant medication could be discontinued if the physician thinks it is appropriate to do so or even continue with the medication if the physician thinks that bleeding could be handled with local hemostatic measures, as in the case when the patient is taking aspirins.

Hematomas and ecchymosis are the result of a surgery procedure and are usually proportional to the magnitude of the intervention. Blood collected under the mucosa and skin are known as bruises and generally cause a feeling of esthetical discomfort to patients, but in some days reabsorption occurs and solves the disgusting aspect of the zone and surroundings (because coagulated blood frequently moves through the anatomy in a descendent trajectory)(fig. 11).

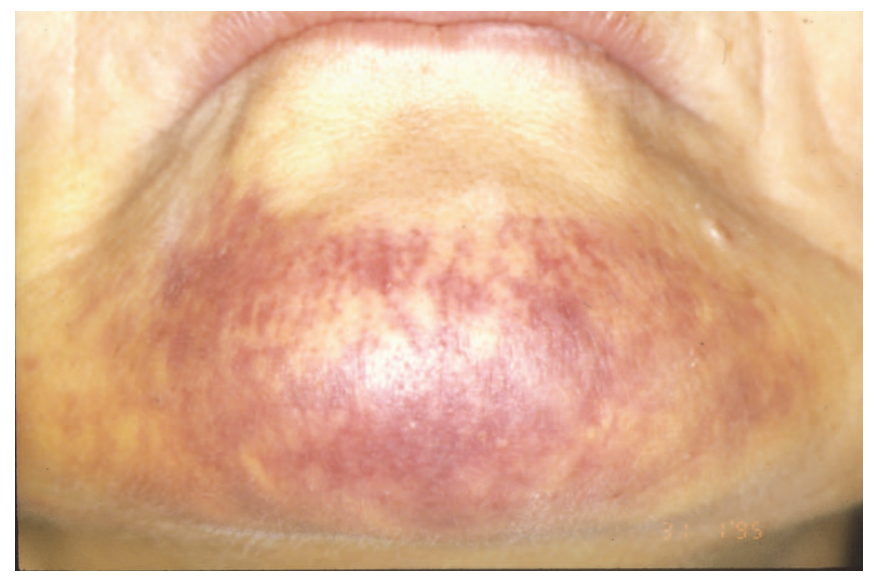

Fig. 11. Ecchymosis are the result of a intermental surgery procedure. 


\subsection{Emphysema}

Tissue emphysema is one of these early complications caused by inadvertent insufflation propulsion of air into tissues under skin or mucous membranes, air from a high-speed handpiece, an air/water syringe, an air polishing unit or an air abrasive device can be projected into a sulcus, surgical wound, or a laceration in the mouth (Liebenberg \& Crawford, 1997); it is a rare complication, though it can lead to severe consequences (McKenzie \& Rosenberg, 2009). The use of abrasive air in implantology, or a laser device as a way to remove residues from an implant surface, has been suggested in the treatment of periimplantitis to facilitate decontamination. The chance for the occurrence of emphysema process during this cleansing maneuver is higher than that of the surgical process since the device uses mechanical motors. This complication occurs when pressurized-air devises are used to remove periodontal and peri-implantation calculi in the maintenance period, as Bergendal et al. (Bergendal et al., 1990) report in a case concerning an acute subcutaneous emphysema.

The air can follow facial planes and create a unilateral enlargement of the fascial and/or sub-mandibular regions. The region with a swelling does normally produce a crackling sensation (crepitation on palpation) as the gas is pushed through the tissue. The crackling sound is pathognomonic of tissue emphysemas, even when discomfort is not reported.

These complications could be avoided by using a sterile water jet handpiece with retrograde air insufflation when, besides an associated implantology surgical process, it is necessary to dry a surface (periodontal treatment, laser, shutting, periapical surgery on an adjacent tooth). The use of air abrasives directed on the sulcus should be avoided as well as its use on inflamed tissues with friable margins, so manual curettage is the best option.

Treatment usually consists on prescribing antibiotics and a mild analgesic therapy, close observation, saline rinses, light massage, apply heat packs and provide mental comfort to patients. The problem does normally solve in 3-10 days.

\subsection{Mucosal dehiscence}

This is a soft tissue complication that can develop infections in the surgical area and implant and/or graft failures that can lead to unfortunate esthetic results. As a rule, surgical wound dehiscences are associated with patients that have scarring problems due to a poor-quality mucosa (thin biotype, traumatized or cicatricial type), heavy smokers, patients treated with corticosteroids, diabetics, or irradiated patients (Lee \& Thiele, 2010) (fig. 12). Another factor leading to surgical wound dehiscence is flap closure under tension, for it has been established that a higher tension causes a more frequent onset of these complications (Lee \& Thiele, 2010).

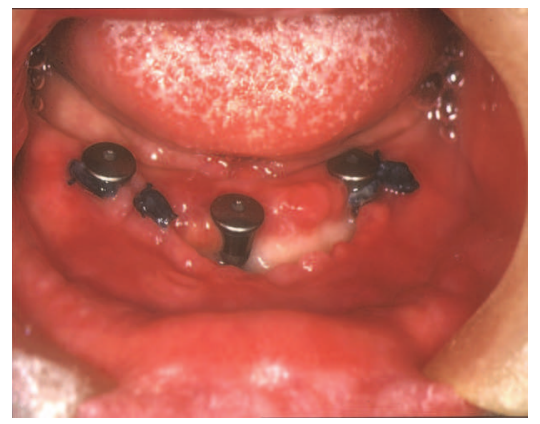

Fig. 12. Wound dehiscence at one week post surgery in a diabetic patient with oral candidiasis. 
Many different solutions have been suggested to prevent dehiscence, in addition to flap management, to guarantee the success of bone regeneration (Park \& Wang, 2007)(fig. 13). A study by Torres et al. established the efficacy of using platelet-rich plasma (PRP) on titanium meshes to prevent the occurrence dehiscences in all the cases described (Torres et al., 2010).

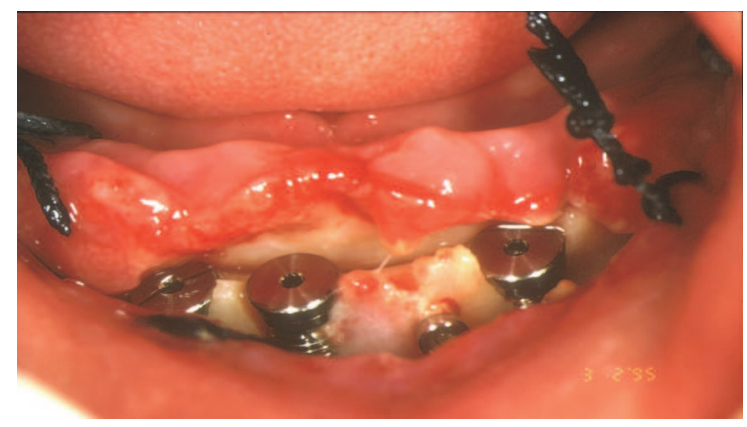

Fig. 13. Wound dehiscence in a case of bone regeneration with collagen membrane (one week control).

The use of free connective tissue grafts may be highly useful for both guaranteeing the closure of the wound and the enlargement of the mucosa thickness around implants, all of which allows better esthetical results in the long run as well as the maintenance of periimplant health (Speroni et al., 2010; Stimmelmayr et al., 2010). El Chaar describes the good results observed in the use of palatal pedicle connective tissue grafts to facilitate the primary closure of a post-exodontic alveolus (El Chaar, 2010), or an acellular dermal matrix interposed between the lap and the subjacent bone (Taylor et al., 2010; Park, 2006).

The use of dense politetraphluoroethilene (d-PTFE) membranes has been suggested to cover the regeneration zones; the benefit of this material resides in that it does not need to be completely covered by the flap since its internal surface does not become contaminated, which is an advantage over other type of membranes (Barber et al., 2007).

A mucosal dehiscence associated with a sinus lift technique represents an aggravating factor that can lead to an infection of the graft material, an acute sinusitis, or an oroantral fistula (Watzak et al., 2005). The management of these abnormal tracts is, depending on the size, laborious and requires well-designed flaps. The use of mono-cortical grafts of intraoral origin (Watzak et al., 2005) or PRP associated with a mucogingival plastia has also been suggested (DePoi et al., 2007).

\subsection{Implant fracture}

Fracture of prosthetic retaining screws is more common than implant fracture and it is normally due to a metal fatigue following an overload of materials (Al Jabbari et al, 2008). An implant fracture seems to be an infrequent complication (among 0,2 y 1,5\% of cases ) (Eckert et al., 2000) that could be ascribed to different reasons: defects in the implant design or materials used in their construction, a non-passive union between the implant and the prosthesis or by mechanical overload, specially cantilevers in fixed prostheses, occlusal overload or/ and parafunctional habits (Al Quran et al., 2009; Mendonca et al., 2009) (fig. 14). The incidence of these complications is higher in implants supporting fixed partial prosthesis than in complete edentulous patients. 
This complication is frequently managed by the removal of the implant and its replacement by another one (Cardoso Lde et al., 2010; Gargallo-Albiol et al., 2008) (fig. 15); nevertheless, some cases describe the use of the remnant part of the dental fixture to rebuild a new prosthesis when is possible (Mendonca et al., 2009).

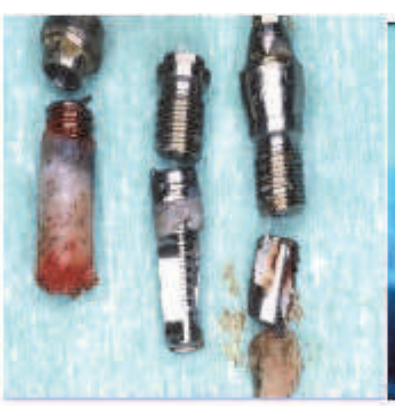

(a)

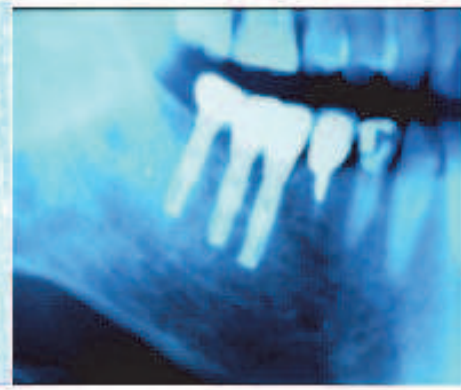

(b)

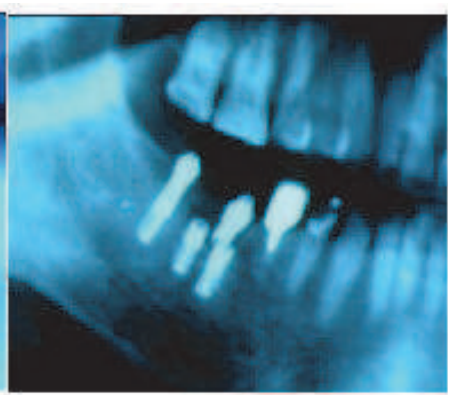

(c)

Fig. 14. (a) Implants retrieved in molar region in a patient with parafunctional habit. (b) Implant rehabilitation). (c) Implants fractured.

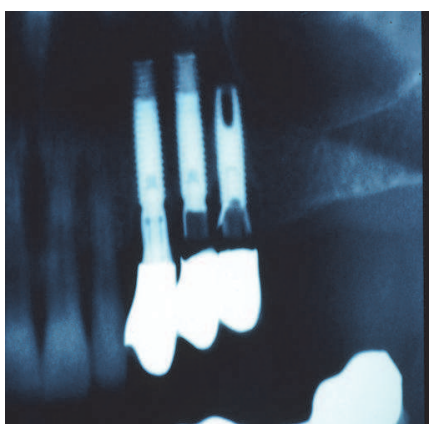

(a)

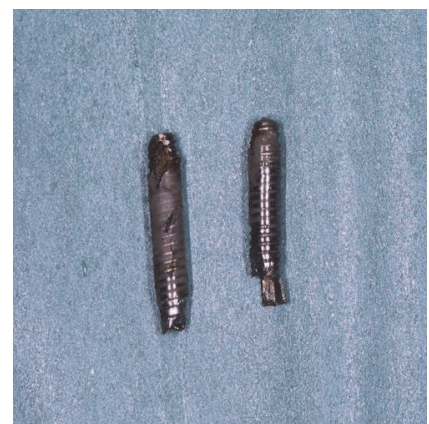

(b)

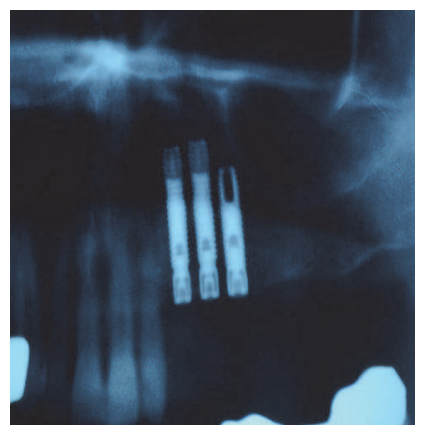

(c)

Fig. 15. (a) Implant fractured in maxillary posterior region. (b) Implants retrieved. (c) Substitution for a wider diameter in the same surgery. 
More than $80 \%$ of factures are located in the molar and premolar regions, and most of them occur 3-4 years after being loaded (Kohal et al., 2010; Gargallo-Albiol et al., 2008) (fig. 16).

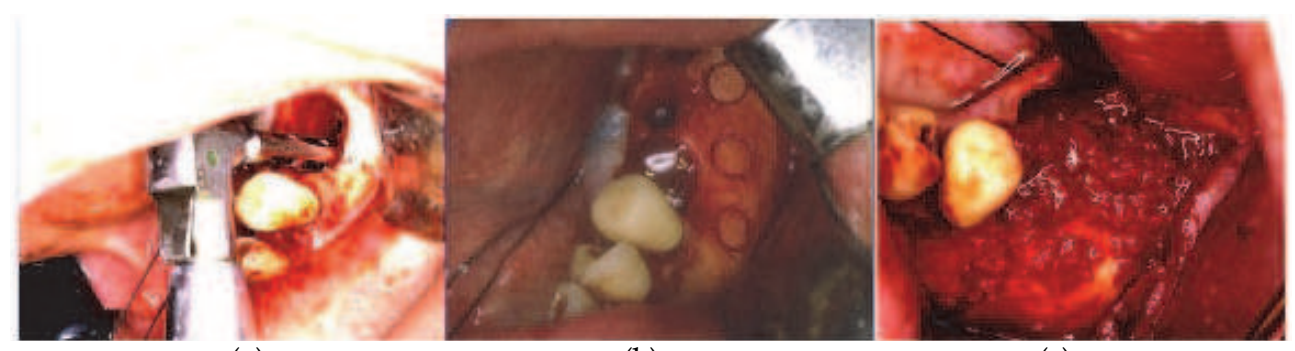

(a)

(b)

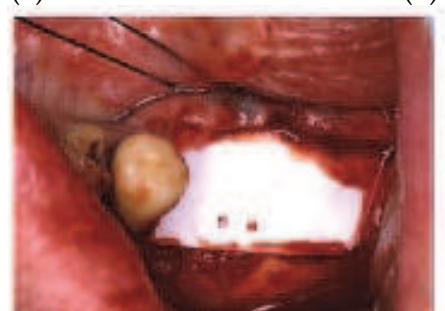

(d)

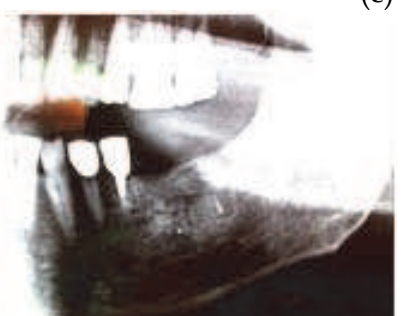

(e)

Fig. 16. Sequence of treatment of an implant fractured. (a) Retrieval with a trephine. (b) Bone harvesting for osseous regeneration. (c) Filling of the osseous defect. (d) Collagen membrane. (e) Image of the control 6 months later.

\subsection{Infection}

Infection of the implant is a common cause of failure but the efficacy of prophylactic antibiotics for dental implant placement seems not influence in risk of implant failure and other complications (Esposito et al., 2010a; 180 Esposito et al., 2010b; Anitua et al., 2009).

Microorganisms found in a periimplantitis are very similar to those found in chronic periodontitis, and the most outstanding are as follows: anaerobic Gram negative bacillus (Porphyromonas gingivalis and Prevotella intermedia), anaerobic Gram negative coccus (Veillonella spp) and the spiroquettes, such as Treponema denticola (Sanchez-Garces \& GayEscoda, 2004). Nowadays, antibiotics are not accepted as the main treatment for periimplantitis, as it is considered a disease with a bad prognosis and predictability that formerly required implant removal (Pye et al., 2009) (fig. 17). This condition requires, on account of its importance and frequency, it own a chapter, so it will not be extensively developed here.

A recent complication detected in the last years is the use of oral bisphosphonates. This medication is broadly used to treat osteoporosis, bones diseases, such as Paget's disease, and osseous metastasis in malign neoplasias. The most common presentations of oral bisphosphonates are Alendronate and Risedronate. On the one hand, they are mainly used for treating osteoporosis and, whereas they curiously are helpful for the long-term stability of the implant, they generate a higher amount of quality bone around the implant surface. This has already been shown in several clinical trials, although a larger amount of patients is 
needed to assure these results (Aspenberg, 2009). In other hand Zahid et al. observed in retrospective radiographic study those patients who take BP are at greater risk of implant failure or thread exposure (Zahid et al., 2010).

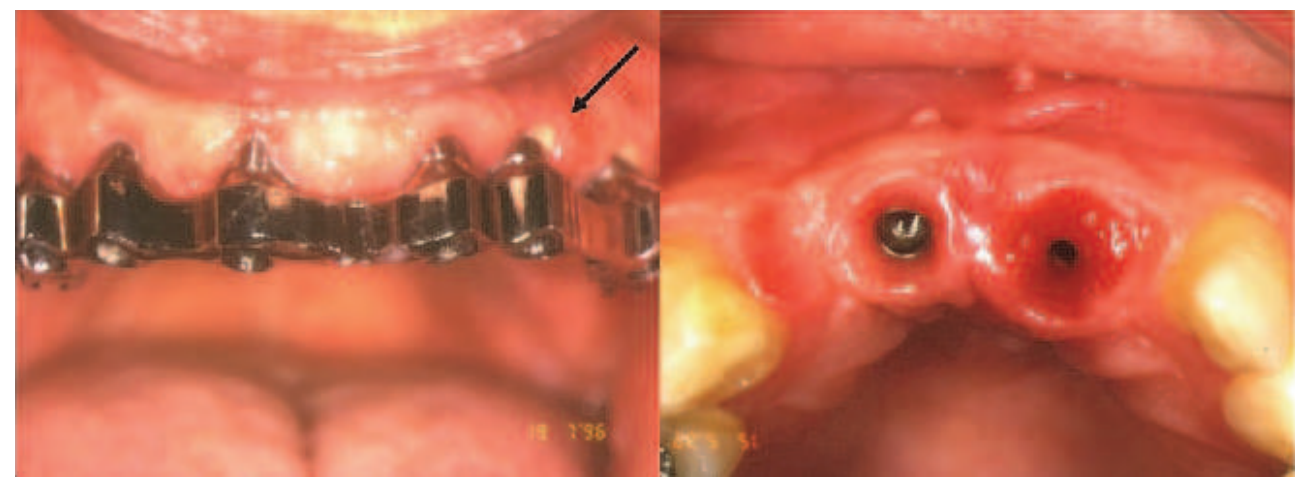

a)

(b)

Fig. 17. (a) Image of periimplantitis and suppuration (arrow). (b) Image of mucositis.

On the other hand, this benefit soon disappears because these drugs can cause osteochemonecrosis of the jaws during the postoperative healing period once the implant has been placed. It has been shown that the length of the medication period is related to the onset and severity of this complication, although more investigation is needed to understand the exact mechanism, while a worldwide consensus is also necessary to prevent the risk posed by osteochemonecrosis after a surgical implant placement. The use of a biochemical marker of bone metabolism as CTX could help to predict the risk in some cases (Lee \& Suzuki, 2009). An article on seven osteochemonecrosis cases treated with low and medium doses of bisphosphonates (oral and venous administration) concluded that it is necessary a strict treatment protocol to obtain good results. The treatment suggested consists in a deep surgical debridement of all the necrotic tissues before performing a regularization procedure on the edge of the bone crest, as well as a primary closure of the wound, avoiding dead spaces (fig. 18). An intravenous antimicrobial therapy should be established for a week to be followed by the oral intake of the drug for another three weeks (Alons et al., 2009). There are at present ten cases in the literature on the use of oral bisphosphonates that caused osteonecrosis. Symptomatology is not well defined at the early stages of this condition, so gammagraphy, using Technetium-99 methylene diphosphonate, $((99) \mathrm{Tc}(\mathrm{m})-\mathrm{MDP})$ could be helpful to diagnose it. In those patients treated with bisphosphonates, controls must be frequent and rigorous and periimplantary hygiene must be carefully performed.

Osteomyelitis $(\mathrm{OM})$ is another scarcely frequent osseous complication of the maxillae. OM is currently related to maxillary bone infections mainly caused by: odontogenic primary infections, after surgical oral procedures (removal of tooth and implant placement); when they are secondary to osteoradionecrosis, or any other osteochemonecrosis processes, or in a postoperative/posttraumatic process.

A retrospective study on 46 patients with OM of the mandible assessed the type of antimicrobial treatments used and the level of resistance against them. Streptococcus viridans 


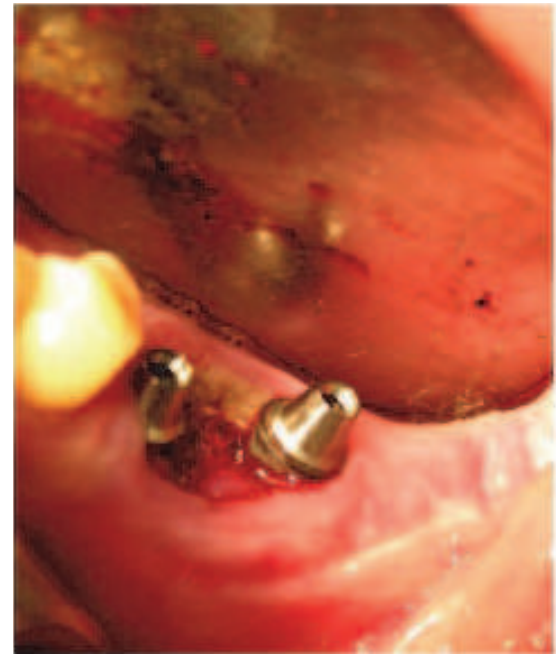

a)

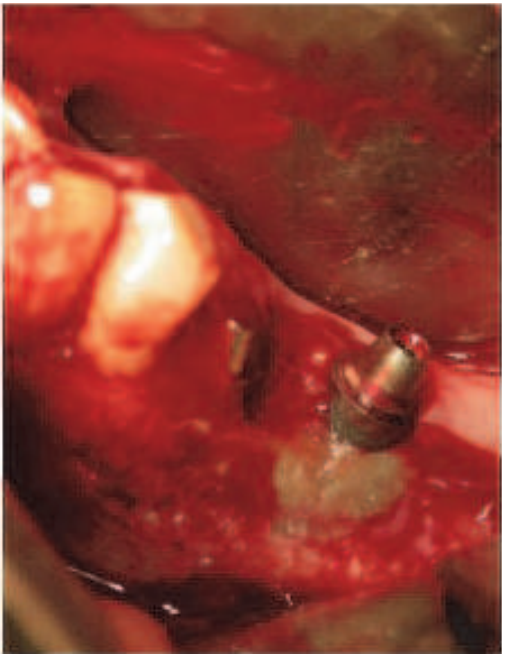

(b)

Fig. 18. (a) Osteonecrosis in a patient treated with biphosphonates i.v. clinical image. (b) Surgical debridement.

was the most frequent pathogen, $81 \%$ were sensible to penicillin and $96 \%$ to fluoroquinolone; however, only $11.5 \%$ were sensitive to clindamycin. Therefore, it was suggested that the drug of choice against maxillae OM should be antimicrobials of the betalactam family. As to patients allergic to penicillin, the best option is the combination of fluoroquinolones and rifampicin, or clindamycin, for a better anaerobic coverage (Pigrau et al., 2009).

\section{Conclusions}

The vast majority of complications in implant surgery can be prevented by correctly selecting patients and treating difficult cases in the most adequate way, while knowing the risks, trying to avoid them with the necessary information and having carefully devised a specific plan for every patient.

\section{References}

Abt, E. (2009). Smoking increases dental implant failures and complications, Evidence-based dentistry Vol. 10 (No. 3): 79-80.

Adell, R., Lekholm, U., Rockler, B. \& Brånemark, P.I. (1981). A 15-year study of osseointegrated implants in the treatment of the edentulous jaw, International journal of oral surgery Vol. 10 (No. 6); 387-416.

Adell, R., Eriksson, B., Lekholm, U., Branemark, P.I. \& Jemt, T. (1990). Long-term follow-up study of osseointegrated implants in the treatment of totally edentulous jaws, The International journal of oral \& maxillofacial implants Vol. 5 (No. 4); 347-359.

Al Jabbari, Y.S., Fournelle, R., Ziebert, G., Toth, J. \& Iacopino, A.M. (2008). Mechanical behavior and failure analysis of prosthetic retaining screws after long-term use in 
vivo. Part 4: Failure analysis of 10 fractured retaining screws retrieved from three patients, Journal of prosthodontics : official journal of the American College of Prosthodontists Vol. 17 (No. 3); 201-210.

Al Quran, F.A., Rashan, B.A. \& Al-Dwairi, Z.N.( 2009). Management of dental implant fractures. A case history", The Journal of oral implantology Vol. 35 (No. 4); 210-214.

Alons, K., Kuijpers, S.C., de Jong, E. \& van Merkesteyn, J.P. (2009). Treating low- and medium-potency bisphosphonate-related osteonecrosis of the jaws with a protocol for the treatment of chronic suppurative osteomyelitis: report of 7 cases, Oral surgery, oral medicine, oral pathology, oral radiology, and endodontic, Vol. 107 (No. 2); e1-7.

Anitua, E., Aguirre, J.J., Gorosabel, A., Barrio, P., Errazquin, J.M., Roman, P., Pla, R., Carrete, J., de Petro, J. \& Orive, G. (2009). A multicentre placebo-controlled randomised clinical trial of antibiotic prophylaxis for placement of single dental implants, European journal of oral implantology Vol. 2 (No. 4); 283-292.

Annibali, S., La Monaca, G., Tantardini, M. \& Cristalli, M.P. (2009). The Role of the Template in Prosthetically Guided Implantology, Journal of Prosthodontics Vol. 18 (No. 2); 177183.

Arisan, V., Karabuda, C.Z. \& Ozdemir, T. (2010). Implant surgery using bone- and mucosasupported stereolithographic guides in totally edentulous jaws: surgical and postoperative outcomes of computer-aided vs. standard techniques, Clinical oral implants research Vol. 21 (No. 9);980-988.

Aspenberg, P.(2009). Bisphosphonates and implants: an overview, Acta orthopaedica Vol. 80 (No. 1);119-123.

Barber, H.D., Lignelli, J., Smith, B.M. \& Bartee, B.K. (2007). Using a dense PTFE membrane without primary closure to achieve bone and tissue regeneration, Journal of oral and maxillofacial surgery : official journal of the American Association of Oral and Maxillofacial Surgeons Vol. 65 ( No. 4);748-752.

Becker, J., Al-Nawas, B., Klein, M.O., Schliephake, H., Terheyden, H. \& Schwarz, F. (2009). Use of a new cross-linked collagen membrane for the treatment of dehiscence-type defects at titanium implants: a prospective, randomized-controlled double-blinded clinical multicenter study", Clinical oral implants research Vol. 20 (No. 7);742-749.

Becker, C.M., Wilson, T.G.,Jr \& Jensen, O.T. (2011). Minimum criteria for immediate provisionalization of single-tooth dental implants in extraction sites: a 1-year retrospective study of 100 consecutive cases, Journal of oral and maxillofacial surgery: official journal of the American Association of Oral and Maxillofacial Surgeons, Vol. 69 (No. 2);491-497.

Bellini, C.M., Romeo, D., Galbusera, F., Taschieri, S., Raimondi, M.T., Zampelis, A. \& Francetti, L. (2009). Comparison of tilted versus nontilted implant-supported prosthetic designs for the restoration of the edentuous mandible: a biomechanical study, The International journal of oral $\mathcal{E}$ maxillofacial implants, Vol. 24 (No. 3);511517.

Bergendal, T., Forsgren, L., Kvint, S. \& Lowstedt, E. (1990). The effect of an airbrasive instrument on soft and hard tissues around osseointegrated implants. A case report, Swedish dental journal, Vol. 14 (No. 5);219-223. 
Bergermann, M., Donald, P.J. \& aWengen, D.F. (1992). Screwdriver aspiration. A complication of dental implant placement, International journal of oral and maxillofacial surgery Vol. 21 (No. 6); 339-341.

Borgonovo, A., Fabbri, A., Boninsegna, R., Dolci, M. \& Censi, R. (2010). Displacement of a dental implant into the maxillary sinus: case series, Minerva stomatologica, Vol. 59 (No. 1-2);45-54.

Bornstein, M.M., Cionca, N. \& Mombelli, A. (2009). Systemic conditions and treatments as risks for implant therapy, The International journal of oral $\mathcal{E}$ maxillofacial implants Vol. 24 (Suppl);12-27.

Brennan, M.T., Wynn, R.L. \& Miller, C.S.( 2007). Aspirin and bleeding in dentistry: an update and recommendations", Oral surgery, oral medicine, oral pathology, oral radiology, and endodontics, Vol. 104 (No. 3);316-323.

Buser, D.; Mericske-stern, R., Pierre Bernard, J.P., Behneke, A., Behneke, N., Hirt, H.P., Belser, U.C. \& Lang, N.P. (1997). Long-term evaluation of non-submerged ITI implants. Part 1: 8-year life table analysis of a prospective multi-center study with 2359 implants, Clinical oral implants research, Vol. 8 (No. 3);161-172.

Buser, D.; Von Arx, T., Ten Bruggenkate, C. \& Weingart, D.( 2000). Basic surgical principles with ITI implants Note, Clinical oral implants research, Vol. 11, 59-68.

Cannizzaro, G., Leone, M. \& Esposito, M. (2007). Immediate functional loading of implants placed with flapless surgery in the edentulous maxilla: 1-year follow-up of a single cohort study, The International journal of oral \& maxillofacial implants, Vol. 22 (No. 1);87-95.

Cannizzaro, G., Leone, M., Consolo, U., Ferri, V. \& Esposito, M.(2008). Immediate functional loading of implants placed with flapless surgery versus conventional implants in partially edentulous patients: a 3-year randomized controlled clinical trial, The International journal of oral \& maxillofacial implant Vol. 23 (No. 5);867-875.

Cardoso Lde, C., Luvizuto, E.R., Trevisan, C.L., Garcia, I.R.Jr, Panzarini, S.R. \& Poi, W.R. (2010). Resolution of a titanium implant fracture after a recurrent trauma, Dental traumatology : official publication of International Association for Dental Traumatology Vol. 26 (No. 6);512-515.

Chappuis, V., Suter, V.G. \& Bornstein, M.M. (2009). Displacement of a dental implant into the maxillary sinus: report of an unusual complication when performing staged sinus floor elevation procedures, The International journal of periodontics $\mathcal{E}$ restorative dentistry Vol. 29 (No. 1);81-87.

Chrcanovic, B.R. \& Custodio, A.L. (2009). Mandibular fractures associated with endosteal implants, Oral and maxillofacial surgery Vol. 13 (No. 4);231-238.

Cochran, D.L., Schou, S., Heitz-Mayfield, L.J., Bornstein, M.M., Salvi, G.E. \& Martin, W.C. (2009). Consensus statements and recommended clinical procedures regarding risk factors in implant therapy, The International journal of oral $\&$ maxillofacial implants Vol. 24 (Suppl);86-89.

Cooper, L.F. (2010). Factors influencing primary dental implant stability remain unclear, The journal of evidence-based dental practice Vol. 10 (No. 1);44-45.

Cordaro, L., Rossini, C. \& Mijiritsky, E. (2004). Fracture and displacement of lingual cortical plate of mandibular symphysis following bone harvesting: case report, Implant dentistry Vol. 13 (No. 3);202-206. 
DePoi, R., John, V., Paez de Mendoza, C.Y. \& Gossweiler, M.K. (2007). Development of an oro-antral fistula following sinus elevation surgery: a case report on management using platelet-rich plasma, Journal (Indiana Dental Association) Vol. 86 (No. 4);10-16.

Dreiseidler, T., Mischkowski, R.A., Neugebauer, J., Ritter, L. \& Zoller, J.E. (2009). Comparison of cone-beam imaging with orthopantomography and computerized tomography for assessment in presurgical implant dentistry, The International journal of oral \& maxillofacial implants Vol. 24 (No. 2);216-225.

Dubois, L., de Lange, J., Baas, E. \& Van Ingen, J. (2010). Excessive bleeding in the floor of the mouth after endosseus implant placement: a report of two cases", International journal of oral and maxillofacial surgery Vol. 39 (No. 4);412-415.

Eckert, S.E., Meraw, S.J., Cal, E. \& Ow, R.K. (2000). Analysis of incidence and associated factors with fractured implants: a retrospective study", The International journal of oral \& maxillofacial implants Vol. 15 (No. 5);662-667.

El Chaar, E.S.(2010). Soft tissue closure of grafted extraction sockets in the posterior maxilla: the rotated pedicle palatal connective tissue flap technique, Implant dentistry Vol. 19 (No. 5);370-377.

Elian, N., Wallace, S., Cho, S.C., Jalbout, Z.N. \& Froum, S. (2005). Distribution of the maxillary artery as it relates to sinus floor augmentation, The International journal of oral \& maxillofacial implant Vol. 20 (No. 5);784-787.

Esposito, M., Cannizzaro, G., Bozzoli, P., Checchi, L., Ferri, V., Landriani, S., Leone, M., Todisco, M., Torchio, C., Testori, T., Galli, F. \& Felice, P. (2010a). Effectiveness of prophylactic antibiotics at placement of dental implants: a pragmatic multicentre placebo-controlled randomised clinical trial, European journal of oral implantology Vol. 3 (No. 2);135-143.

Esposito, M., Grusovin, M.G., Loli, V., Coulthard, P. \& Worthington, H.V. (2010b). Does antibiotic prophylaxis at implant placement decrease early implant failures? A Cochrane systematic review, European journal of oral implantology Vol. 3 (No. 2);101110.

Felisati, G., Lozza, P., Chiapasco, M. \& Borloni, R. (2007). Endoscopic removal of an unusual foreign body in the sphenoid sinus: an oral implant, Clinical oral implants research Vol. 18 (No. 6);776-780.

Frenken, J.W., Zijderveld, S.A., van den Bergh, J.P., Huisman, F.W. \& Cune, M.S. (2010). Haematoma of the floor of the mouth following implant surgery, Nederlands tijdschrift voor tandheelkunde Vol. 117 (No. 1);17-21.

Galindo, P., Sanchez-Fernandez, E., Avila, G., Cutando, A. \& Fernandez, J.E. (2005). Migration of implants into the maxillary sinus: two clinical cases, The International journal of oral \& maxillofacial implants Vol. 20 (No. 2);291-295.

Garfunkel, A.A., Galili, D., Findler, M., Lubliner, J. \& Eldor, A.(1999). Bleeding tendency: a practical approach in dentistry, Compendium of continuing education in dentistry (Jamesburg, N.J.: 1995) Vol. 20 (No. 9);836-8, 840-2, 844 passim.

Garg, A. (2010). Pathophysiology of tobacco use and wound healing", Dental implantology update Vol. 21 (No. 1);1-4.

Gargallo Albiol, J., Satorres-Nieto, M., Puyuelo Capablo, J.L., Sanchez Garces, M.A., Pi Urgell, J. \& Gay Escoda, C. (2008). Endosseous dental implant fractures: an analysis of 21 cases, Medicina oral, patologia oral y cirugia bucal Vol. 13 (No. 2);E124-8. 
Gotta, S., Sarnachiaro, G.O. \& Tarnow, D.P. (2008). Distraction osteogenesis and orthodontic therapy in the treatment of malpositioned osseointegrated implants: a case report, Practical procedures \& aesthetic dentistry : PPAD Vol. 20 (No. 7);401-405.

Greenstein, G., Cavallaro, J., Romanos, G. \& Tarnow, D. (2008). Clinical recommendations for avoiding and managing surgical complications associated with implant dentistry: a review, Journal of periodontology Vol. 79 (No. 8);1317-1329.

Griffa, A., Viterbo, S. \& Boffano, P. (2010). Endoscopic-assisted removal of an intraorbital dislocated dental implant, Clinical oral implants research Vol. 21 (No. 7);778-780.

Haben, C.M., Balys, R. \& Frenkiel, S. (2003). Dental implant migration into the ethmoid sinus, The Journal of otolaryngology Vol. 32 (No. 5);342-344.

Hassan, K.S. (2009). Autogenous bone graft combined with polylactic polyglycolic acid polymer for treatment of dehiscence around immediate dental implants, Oral surgery, oral medicine, oral pathology, oral radiology, and endodontics Vol. 108 (No. 5);e19-25.

Hegedus, F. \& Diecidue, R.J. (2006). Trigeminal nerve injuries after mandibular implant placement--practical knowledge for clinicians, The International journal of oral $\mathcal{E}$ maxillofacial implants Vol. 21 (No. 1);111-116.

Hur, Y., Tsukiyama, T., Yoon, T.H. \& Griffin, T. (2010). Double flap incision design for guided bone regeneration: a novel technique and clinical considerations, Journal of periodontology Vol. 81 (No. 6);945-952.

Javed, F., Almas, K., Crespi, R. \& Romanos, G.E. (2011). Implant surface morphology and primary stability: is there a connection?, Implant dentistry Vol. 20 (No. 1);40-46.

Jung, R.E., Halg, G.A., Thoma, D.S. \& Hammerle, C.H. (2009). A randomized, controlled clinical trial to evaluate a new membrane for guided bone regeneration around dental implants, Clinical oral implants research Vol. 20 (No. 2);162-168.

Kohal, R.J., Wolkewitz, M. \& Mueller, C. (2010). Alumina-reinforced zirconia implants: survival rate and fracture strength in a masticatory simulation trial, Clinical oral implants research Vol. 21 (No. 12);1345-1352.

Lang, N.P., Wilson, T.G. \& Corbet, E.F. (2000). Biological complications with dental implants: their prevention, diagnosis and treatment Note, Clinical oral implants research Vol. 11;146-155.

Lee, C.Y. \& Suzuki, J.B. (2009). CTX biochemical marker of bone metabolism. Is it a reliable predictor of bisphosphonate-associated osteonecrosis of the jaws after surgery? Part I: biological concepts with a review of the literature, Implant dentistry Vol. 18 (No. 6);492-500.

Lee, C.Y. (2010). Brisk, prolonged pulsatile hemorrhage during the sinus graft procedure: a case report with discussion on intra-operative hemostatic management, Implant dentistry Vol. 19 (No. 3);189-195.

Lee, S. \& Thiele, C. (2010). Factors associated with free flap complications after head and neck reconstruction and the molecular basis of fibrotic tissue rearrangement in preirradiated soft tissue, Journal of oral and maxillofacial surgery : official journal of the American Association of Oral and Maxillofacial Surgeons Vol. 68 (No. 9);2169-2178.

Liebenberg, W.H. \& Crawford, B.J. (1997). Subcutaneous, orbital, and mediastinal emphysema secondary to the use of an air-abrasive device, Quintessence international (Berlin, Germany : 1985) Vol. 28 (No. 1);31-38. 
Lindfors, L.T., Tervonen, E.A., Sandor, G.K. \& Ylikontiola, L.P. (2010). Guided bone regeneration using a titanium-reinforced ePTFE membrane and particulate autogenous bone: the effect of smoking and membrane exposure, Oral surgery, oral medicine, oral pathology, oral radiology, and endodontic Vol. 109 (No. 6);825-830.

Mardinger, O., Manor, Y., Mijiritsky, E. \& Hirshberg, A. (2007). Lingual perimandibular vessels associated with life-threatening bleeding: an anatomic study, The International journal of oral \& maxillofacial implants Vol. 22 (No. 1);127-131.

Martin, W., Lewis, E. \& Nicol, A. (2009). Local risk factors for implant therapy, The International journal of oral \& maxillofacial implants Vol. 24 (Suppl);28-38.

Mayfield, L., Nobreus, N., Attstrom, R. \& Linde, A. (1997). Guided bone regeneration in dental implant treatment using a bioabsorbable membrane, Clinical oral implants research Vol. 8 (No. 1);10-17.

McKenzie, W.S. \& Rosenberg, M. (2009). Iatrogenic subcutaneous emphysema of dental and surgical origin: a literature review, Journal of oral and maxillofacial surgery : official journal of the American Association of Oral and Maxillofacial Surgeons Vol. 67 (No. 6);1265-1268.

Mendonca, G., Mendonca, D.B., Fernandes Neto, A.J. \& Neves, F.D.(2008). Use of distraction osteogenesis for repositioning of an osseointegrated implant: a case report, The International journal of oral \& maxillofacial implants Vol. 23 (No. 3);551-555.

Mendonca, G., Mendonca, D.B., Fernandes-Neto, A.J. \& Neves, F.D.(2009). Management of fractured dental implants: a case report, Implant dentistry Vol. 18 (No. 1);10-16.

Merli, M., Bernardelli, F. \& Esposito, M. (2008). Computer-guided flapless placement of immediately loaded dental implants in the edentulous maxilla: a pilot prospective case series, European journal of oral implantology Vol. 1 (No. 1);61-69.

Misch, C.E. \& Resnik, R. (2010). Mandibular nerve neurosensory impairment after dental implant surgery: management and protocol, Implant dentistry Vol. 19 (No. 5);378386.

Nahlieli, O., Moshonov, J., Zagury, A., Michaeli, E. \& Casap, N. (2011). Endoscopic approach to dental implantology, Journal of oral and maxillofacial surgery : official journal of the American Association of Oral and Maxillofacial Surgeons Vol. 69 (No. 1);186-191.

Napenas, J.J., Hong, C.H., Brennan, M.T., Furney, S.L., Fox, P.C. \& Lockhart, P.B. (2009). The frequency of bleeding complications after invasive dental treatment in patients receiving single and dual antiplatelet therapy, Journal of the American Dental Association (1939) Vol. 140 (No. 6);690-695.

Neugebauer, J., Scheer, M., Mischkowski, R.A., An, S.H., Karapetian, V.E., Toutenburg, H. \& Zoeller, J.E. (2009). Comparison of torque measurements and clinical handling of various surgical motors, The International journal of oral $\mathcal{E}$ maxillofacial implants Vol. 24 (No. 3);469-476.

Oduncuoglu, B.F., Alaaddinoglu, E.E., Oguz, Y., Uckan, S. \& Erkut, S. (2011). Repositioning a Prosthetically Unfavorable Implant by Vertical Distraction Osteogenesis, Journal of oral and maxillofacial surgery : official journal of the American Association of Oral and Maxillofacial Surgeons, April 4 (Epub ahead of print).

Oh, T.J., Meraw, S.J., Lee, E.J., Giannobile, W.V. \& Wang, H.L. (2003). Comparative analysis of collagen membranes for the treatment of implant dehiscence defects, Clinical oral implants research Vol. 14 (No. 1);80-90. 
Oh, W.S., Roumanas, E.D. \& Beumer, J.,3rd (2010). Mandibular fracture in conjunction with bicortical penetration, using wide-diameter endosseous dental implants, Journal of prosthodontics : official journal of the American College of Prosthodontists Vol. 19 (No. 8);625-629.

Ozcelik, O., Haytac, M.C. \& Akkaya, M.(2005). Iatrogenic trauma to oral tissues, Journal of periodontology Vol. 76 (No. 10);1793-1797.

Padmanabhan, T.V. \& Gupta, R.K. (2010). Comparison of crestal bone loss and implant stability among the implants placed with conventional procedure and using osteotome technique: a clinical study, The Journal of oral implantology Vol. 36 (No. 6);475-483.

Park, J.B. (2006). Increasing the width of keratinized mucosa around endosseous implant using acellular dermal matrix allograft, Implant dentistry Vol. 15 (No. 3);275-281.

Park, S.H. \& Wang, H.L. (2007). Clinical significance of incision location on guided bone regeneration: human study, Journal of periodontology Vol. 78 (No. 1);47-51.

Parnia, F., Fard, E.M., Mahboub, F., Hafezeqoran, A. \& Gavgani, F.E. (2010). Tomographic volume evaluation of submandibular fossa in patients requiring dental implants, Oral surgery, oral medicine, oral pathology, oral radiology, and endodontics Vol. 109 (No. 1);e32-6.

Pigrau, C., Almirante, B., Rodriguez, D., Larrosa, N., Bescos, S., Raspall, G. \& Pahissa, A. (2009). Osteomyelitis of the jaw: resistance to clindamycin in patients with prior antibiotics exposure, European journal of clinical microbiology $\mathcal{E}$ infectious diseases : official publication of the European Society of Clinical Microbiology Vol. 28 (No. 4);317323.

Pingarron Martin, L., Moran Soto, M.J., Sanchez Burgos, R. \& Burgueno Garcia, M. (2010). Bronchial impaction of an implant screwdriver after accidental aspiration: report of a case and revision of the literature, Oral and maxillofacial surgery Vol. 14 (No. 1);4347.

Pye, A.D., Lockhart, D.E., Dawson, M.P., Murray, C.A. \& Smith, A.J.(2009). A review of dental implants and infection, The Journal of hospital infection Vol. 72 (No. 2);104-110.

Queral-Godoy, E., Vazquez-Delgado, E., Okeson, J.P. \& Gay-Escoda, C. (2006). Persistent idiopathic facial pain following dental implant placement: a case report, The International journal of oral \& maxillofacial implants Vol. 21 (No. 1);136-140.

Quirynen, M., Vogels, R., Alsaadi, G., Naert, I., Jacobs, R. \& van Steenberghe, D.(2005). Predisposing conditions for retrograde peri-implantitis, and treatment suggestions, Clinical oral implants research Vol. 16 (No. 5);599-608.

Ramotar, H., Jaberoo, M.C., Koo Ng, N.K., Pulido, M.A. \& Saleh, H.A.(2010). Image-guided, endoscopic removal of migrated titanium dental implants from maxillary sinus: two cases, The Journal of laryngology and otology Vol. 124 (No. 4);433-436.

Reychler, H. \& Olszewski, R.(2010). Intracerebral penetration of a zygomatic dental implant and consequent therapeutic dilemmas: case report, The International journal of oral $\mathcal{E}$ maxillofacial implants Vol. 25 (No. 2);416-418.

Ridaura-Ruiz, L., Figueiredo, R., Guinot-Moya, R., Pinera-Penalva, M., Sanchez-Garces, M.A., Valmaseda-Castellon, E. \& Gay-Escoda, C.(2009). Accidental displacement of dental implants into the maxillary sinus: a report of nine cases, Clinical implant dentistry and related research Vol. 11 (Suppl 1);e38-45. 
Rodriguez-Lozano, F.J., Sanchez-Perez, A., Moya-Villaescusa, M.J., Rodriguez-Lozano, A. \& Saez-Yuguero, M.R.(2010). Neuropathic orofacial pain after dental implant placement: review of the literature and case report, Oral surgery, oral medicine, oral pathology, oral radiology, and endodontics Vol. 109 (No. 4);e8-12.

Romanos, G.E. (2009). Nonsurgical prosthetic management of mandibular fracture associated with dental implant therapy: a case report, The International journal of oral $\mathcal{E}$ maxillofacial implants Vol. 24 (No. 1);143-146.

Rosen, P.S. \& Reynolds, M.A. (2001). Guided bone regeneration for dehiscence and fenestration defects on implants using an absorbable polymer barrier, Journal of periodontology Vol. 72 (No. 2);250-256.

Sanchez-Garces, M.A. \& Gay-Escoda, C. (2004). Periimplantiti", Medicina oral, patologia oral y cirugia bucal Vol. 9 (Suppl);69-74; 63-9.

Sanz, M., Naert, I. \& Working Group 2 (2009). Biomechanics/risk management (Working Group 2), Clinical oral implants research Vol. 20 (Suppl 4);107-111.

Seong, W.J., Kim, U.K., Swift, J.Q., Hodges, J.S. \& Ko, C.C. (2009). Correlations between physical properties of jawbone and dental implant initial stability, The Journal of prosthetic dentistry Vol. 101 (No. 5);306-318.

Siciliano, V.I., Salvi, G.E., Matarasso, S., Cafiero, C., Blasi, A. \& Lang, N.P.(2009). Soft tissues healing at immediate transmucosal implants placed into molar extraction sites with buccal self-contained dehiscences. A 12-month controlled clinical trial, Clinical oral implants research Vol. 20 (No. 5);482-488.

Speroni, S., Cicciu, M., Maridati, P., Grossi, G.B. \& Maiorana, C. (2010). Clinical investigation of mucosal thickness stability after soft tissue grafting around implants: a 3-year retrospective study, Indian journal of dental research : official publication of Indian Society for Dental Research Vol. 21 (No. 4);474-479.

Steigmann, M.(2008). Aesthetic flap design for correction of buccal fenestration defects, Practical procedures \& aesthetic dentistry : PPAD Vol. 20 (No. 8);487-93; quiz 494.

Stimmelmayr, M., Allen, E.P., Reichert, T.E. \& Iglhaut, G.(2010). Use of a combination epithelized-subepithelial connective tissue graft for closure and soft tissue augmentation of an extraction site following ridge preservation or implant placement: description of a technique, The International journal of periodontics $\mathcal{E}$ restorative dentistry Vol. 30 (No. 4);375-381.

Taylor, J.B., Gerlach, R.C., Herold, R.W., Bisch, F.C. \& Dixon, D.R. (2010). A modified tensionless gingival grafting technique using acellular dermal matrix, The International journal of periodontics \& restorative dentistry Vol. 30 (No. 5);513-521.

Testori, T., Rosano, G., Taschieri, S. \& Del Fabbro, M. (2010). Ligation of an unusually large vessel during maxillary sinus floor augmentation. A case report, European journal of oral implantology Vol. 3 (No. 3);255-258.

Tiwana, P.S., Abraham, M.S., Kushner, G.M. \& Alpert, B. (2009). Management of atrophic edentulous mandibular fractures: the case for primary reconstruction with immediate bone grafting, Journal of oral and maxillofacial surgery : official journal of the American Association of Oral and Maxillofacial Surgeons Vol. 67 (No. 4);882-887.

Torres, J., Tamimi, F., Alkhraisat, M.H., Manchon, A., Linares, R., Prados-Frutos, J.C., Hernandez, G. \& Lopez Cabarcos, E.(2010). Platelet-rich plasma may prevent titanium-mesh exposure in alveolar ridge augmentation with anorganic bovine bone, Journal of clinical periodontology Vol. 37 (No. 10);943-951. 
Tozum, T.F., Sencimen, M., Ortakoglu, K., Ozdemir, A., Aydin, O.C. \& Keles, M. (2006). Diagnosis and treatment of a large periapical implant lesion associated with adjacent natural tooth: a case report, Oral surgery, oral medicine, oral pathology, oral radiology, and endodontics Vol. 101 (No. 6);e132-8.

Watzak, G., Tepper, G., Zechner, W., Monov, G., Busenlechner, D. \& Watzek, G. (2005). Bony press-fit closure of oro-antral fistulas: a technique for pre-sinus lift repair and secondary closure, Journal of oral and maxillofacial surgery : official journal of the American Association of Oral and Maxillofacial Surgeons Vol. 63 (No. 9);1288-1294.

Welcker, K., Nakashima, M. \& Branscheid, D. (2005). Aspiration of dental implant -- reasons, management and prevention], Pneumologie (Stuttgart, Germany Vol. 59 (No. 3);174177.

Wennström, J.L., Ekestubbe, A., Gröndahl, K., Karlsson, S. \& Lindhe, J. (2005). Implantsupported single-tooth restorations: a 5-year prospective study, Journal of clinical periodontology Vol. 32 (No. 6);567-574.

Worthington, P. (1996). Ingested foreign body associated with oral implant treatment: report of a case, The International journal of oral \& maxillofacial implants Vol. 11 (No. 5)679681.

Zahid, T., Wang, B.Y. \& Cohen, R. (2010). Influence of Bisphosphonates on Alveolar Bone Loss around Osseointegrated Implants, The Journal of oral implantology, Jun 16 (Epub ahead of print).

Zhou, W., Han, C., Li, D., Li, Y., Song, Y. \& Zhao, Y. (2009). Endodontic treatment of teeth induces retrograde peri-implantitis, Clinical oral implants research Vol. 20 (No. 12);1326-1332. 


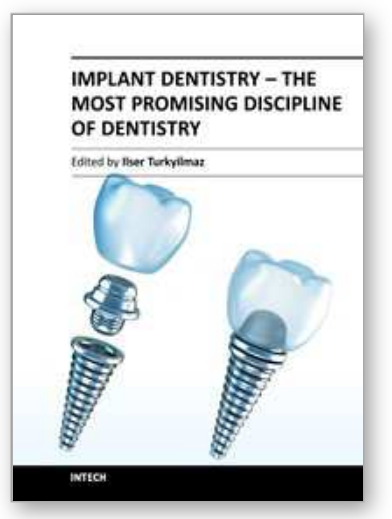

\author{
Implant Dentistry - The Most Promising Discipline of Dentistry \\ Edited by Prof. Ilser Turkyilmaz
}

ISBN 978-953-307-481-8

Hard cover, 476 pages

Publisher InTech

Published online 30, September, 2011

Published in print edition September, 2011

Since Dr. Branemark presented the osseointegration concept with dental implants, implant dentistry has changed and improved dramatically. The use of dental implants has skyrocketed in the past thirty years. As the benefits of therapy became apparent, implant treatment earned a widespread acceptance. The need for dental implants has resulted in a rapid expansion of the market worldwide. To date, general dentists and a variety of specialists offer implants as a solution to partial and complete edentulism. Implant dentistry continues to advance with the development of new surgical and prosthodontic techniques. The purpose of Implant Dentistry - The Most Promising Discipline of Dentistry is to present a comtemporary resource for dentists who want to replace missing teeth with dental implants. It is a text that integrates common threads among basic science, clinical experience and future concepts. This book consists of twenty-one chapters divided into four sections.

\title{
How to reference
}

In order to correctly reference this scholarly work, feel free to copy and paste the following:

Ma Angeles Sánchez Garcés, Jaume Escoda-Francoli and Cosme Gay-Escoda (2011). Implant Complications, Implant Dentistry - The Most Promising Discipline of Dentistry, Prof. Ilser Turkyilmaz (Ed.), ISBN: 978-953-307481-8, InTech, Available from: http://www.intechopen.com/books/implant-dentistry-the-most-promisingdiscipline-of-dentistry/implant-complications

\section{INTECH}

open science | open minds

\author{
InTech Europe \\ University Campus STeP Ri \\ Slavka Krautzeka 83/A \\ 51000 Rijeka, Croatia \\ Phone: +385 (51) 770447 \\ Fax: +385 (51) 686166 \\ www.intechopen.com
}

\author{
InTech China \\ Unit 405, Office Block, Hotel Equatorial Shanghai \\ No.65, Yan An Road (West), Shanghai, 200040, China \\ 中国上海市延安西路65号上海国际贵都大饭店办公楼 405 单元 \\ Phone: +86-21-62489820 \\ Fax: +86-21-62489821
}


(C) 2011 The Author(s). Licensee IntechOpen. This chapter is distributed under the terms of the Creative Commons Attribution-NonCommercialShareAlike-3.0 License, which permits use, distribution and reproduction for non-commercial purposes, provided the original is properly cited and derivative works building on this content are distributed under the same license. 